\title{
Child sex ratio 950- challenges and means to achieve
}

\author{
Rinal Parikh ${ }^{1}$, Kedar Mehta ${ }^{2, *}$ \\ ${ }^{1}$ Intern, ${ }^{2}$ Assistant Professor, Dept. of Community Medicine, GMERS Medical College, Gotri, Vadodara, Gujarat, India
}

*Corresponding Author:

Email: kedar_mehta20@yahoo.co.in

The sex ratio denotes the male to female ratio of a population and is represented internationally as the number of males per 100 females. On the contrary, in India, it is denoted by the number of females per 1,000 males. The sex ratio can be expressed in various forms: sex ratio at birth, child sex ratio or juvenile sex ratio, and sex ratio of the general population.

The biologically normal sex ratio at birth is 105 male births per 100 female births (952 female births per 1,000 male births) under natural circumstances, affirming a male advantage at birth. But as females have an advantage over males in terms of mortality at most ages, under normal circumstances, the male sex ratio declines during childhood and evens out at 100 . The child sex ratio or juvenile sex ratio is defined as the sex ratio in a specific age group, typically $0-6$ or $0-4$ years, and the global norm suggests that the sex ratio at birth (105 male births per 100 female births or 952 female births per 1,000 male births) persists among children as well (United Nations Population Fund, 2013).

The situation in India is particularly disturbing; in 2012, the sex ratio at birth was 908 female births per 1,000 male births (110 male births per 100 female births) and the child sex ratio, in 2011, had plummeted to 918 females aged 0-6 per 1,000 males (109 males per 100 females), from an already dismal 927 in 2001, and 945 in 1991 (as per statistic reports from the government in 2013). Estimates from India suggest some 10 million gender-biased sex-selective abortions had taken place in the period from 1985-2005, worsening the child sex ratio in the nation.

In 2010, the child sex ratio declined in 461 districts which is about three fourth of total districts in the country. In 38 districts decline has been more than 50 points.

The trend of decline in the child sex ratio (CSR) has been unabated since 1961. The decline from 945 in 1991 to 927 in 2001 and further to 918 in 2011 is alarming. This decline in the CSR is a major indicator of women disempowerment. CSR reflects both, prebirth discrimination manifested through gender biased sex selection, and post birth discrimination against girls. Social construct discriminating against girls on the one hand, easy availability, affordability and subsequent misuse of diagnostic tools on the other hand, have been critical in increasing sex selective elimination of girls leading to low child sex ratio.

So, in view of changing scenarios in India from a male chauvinistic society to an equal ground, ensuring gender equality for men and women, the Government of India has set up a goal of achieving a child sex ratio of 950 girls per 1000 boys. But it still has to face a lot of hardships, or rather challenges to accomplish this goal. Various challenges that have lead to a "dearth" of the girl child in the country are: gender biased sex selection and abortion during pregnancy (with increasing cases of illegal $\mathrm{n}$ hazardous abortions), female feticide, female infanticide (drowning the girl child, poisoning, "dudhpiti-the age old method of infanticide", burying the inftant, etc), bias while providing health care, neglected feeding practices for girl child, and many more on record. Increasing medical technologies add up to this dreadful scene, alongwith practices like hypergamy which put the toll of huge dowries on the girl's household, thus diminuting the preference of a female child in some castes. While these challenges continue to pose a threat in achieving the goal of CSR of 950, the government with support of the NGOs as well as the citizens of the nation, has set up policies and schemes to achieve this huge yet attainable goal.

The Government has formulated laws to protect the rights of children, the dignity and individuality of young girls as well as women in order to help them survive independently. These include the PCPNDT Act, Medical Termination of Pregnancy Act (MTP) 1971 and Amendment of 2002, Code of Medical Ethics, The right to free and compulsory education Act, 2009, child marriage restraint act of 1929 , protection of women against sexual harassment at workplace bill, 2010, which ensures safety of women working or entering any workplace as a client or customer in both public and private sectors, along with laws ensuring females to have equal part in inheritance of patriarchal property as well as freedom of work $\mathrm{n}$ equal pay for equal work. 
One of the most recent and perhaps the most active schemes to increase the child sex ratio is the "Beti Bachao, Beti Padhao" Initiative, that has changed the outlook of the country anew. This is being implemented through a national campaign and multi- sectorial action in around 100 districts having low CSR, covering all states and UTs.

The objectives of this initiative include:

1. Prevention of gender biased sex selective discrimination

2. Ensuring survival and protection of girl child

3. Ensuring education and participation of girl child.

Thus, even though the path of achieving the desired child sex ratio-950 is tough; meticulous and dedicated steps towards this, under the vision of our esteemed Prime Minister Mr. Narendra Modi, are already set into motion. The role of mass media, internet, television and social media is unsurpassable in making this target not just the government's target, nut a responsibility of each and every citizen of India.

It is truly said that "children of today are the future of tomorrow", this powerful statement assumes great importance for India as children constitute about one third of our population. So come, lets join hands and work towards making a bright $\mathrm{n}$ steady future for children in our country, saying no to gender inequality, fighting child labor and all other demons that jeopardize the lives of our children. Let the vision of our legendary leaders envisage our minds and safeguard the girl child today, ensuring a day in the near future where India has a society where child sex ratio as well as sex ratio at birth $\mathrm{n}$ in adults does not put us all to shame, but makes us raise our heads in pride. 